\title{
Estética y dinámica visual de la presentación científica. Conceptos básicos
}

\author{
J. González-Tortosa
}

Servicio de Neurocirugía. Hospital Universitario Virgen de la Arrixaca. Murcia

\section{Resumen}

La estética y dinámica visual de la presentación científica es, con frecuencia, un tema para el que se dispone de poco tiempo en nuestro ejercicio profesional. En este artículo se desarrollan conceptos básicos referentes al manejo del color, jerarquía plástica del texto y animación de los gráficos, con normas para que la exposición sea armónica y equilibrada desde el punto de vista visual.

PALABRAS CLAVE: Presentación. Estética. Transiciones. Animación. Color.

Aesthetic and visual dynamics of the presentation. Basic concepts

\section{Summary}

Aesthetic and dynamic aspects of scientific presentations have been scarcely discussed in the medical literature. In this work, basic concepts regarding colour, management, hierarchical disposition of the text, and graphics' animations are briefly described to allow an harmonic and balanced exposition of the visual presentation.

KEY WORDS: Aesthetics presen tions. Slide color. Slide animation. Slide transition.

"La belleza es un acuerdo entre el contenido y la forma" (Henrick Ibsen).

\section{Introducción}

El arte gráfico y sus herramientas informáticas requieren un prolongado tiempo de aprendizaje y maduración. El ejercicio de la neurocirugía no deja mucho margen para ello y nuestros hospitales no suelen tener profesionales que

Recibido: 27-01-05. Aceptado: 17-03-05 nos puedan ayudar. Este artículo pretende dar una información básica y escueta que ayude a mejorar el valor plástico de la presentación en Microsoft ${ }^{\circledR}$ PowerPoint ${ }^{\circledR} 2002$.

El diseño de la presentación. Uso de plantillas o "templates"

Podemos elegir uno de los muchos que nos ofrece el programa, atendiendo al que más se acerque a nuestras necesidades de distribución de texto e imágenes. Pero lo que nos ofrece mas libertad para colocar los objetos que vamos a necesitar a lo largo de toda la presentación, es el diseño en blanco.

\section{El dibujo del fondo o "background"}

Podemos crear el nuestro propio, pero eso es una labor reservada a expertos en el manejo de programas gráficos. Lo más fácil es elegir uno entre los prediseñados por el programa. Debe de ser sencillo para que no se haga dueño de la diapositiva y dejar espacio suficiente para el texto y fotografías. El dibujo de fondo es uno de los lazos de unión entre las diapositivas, por lo que no debe de cambiar a lo largo de toda la exposición y el PowerPoint lo incluye en el "patrón de la diapositiva" o "Master". Sí es aceptable que la primera diapositiva tenga un dibujo diferente, aunque con la misma paleta de colores que se va a utilizar a lo largo de toda la exposición. Esta primera diapositiva suele contener información sobre el autor o autores y su hospital, además del título de la conferencia. Ya que no se puede introducir en el "Patrón de Diapositiva", hay que ponerlo encima de la primera diapositiva, como una imagen insertada.

\section{Conceptos básicos sobre el color}

Isaac Newton dividió la luz blanca en sus diferentes componentes, desde el rojo al azul, pasando por el naranja, amarillo, verde y cian (azul intenso). Unió sus extremos y creó la primera rueda de colores naturales, que modificada, es la que se utiliza hoy (Fig. 1). La rueda compuesta por los colores primarios Rojo, Verde, Azul se denomina 


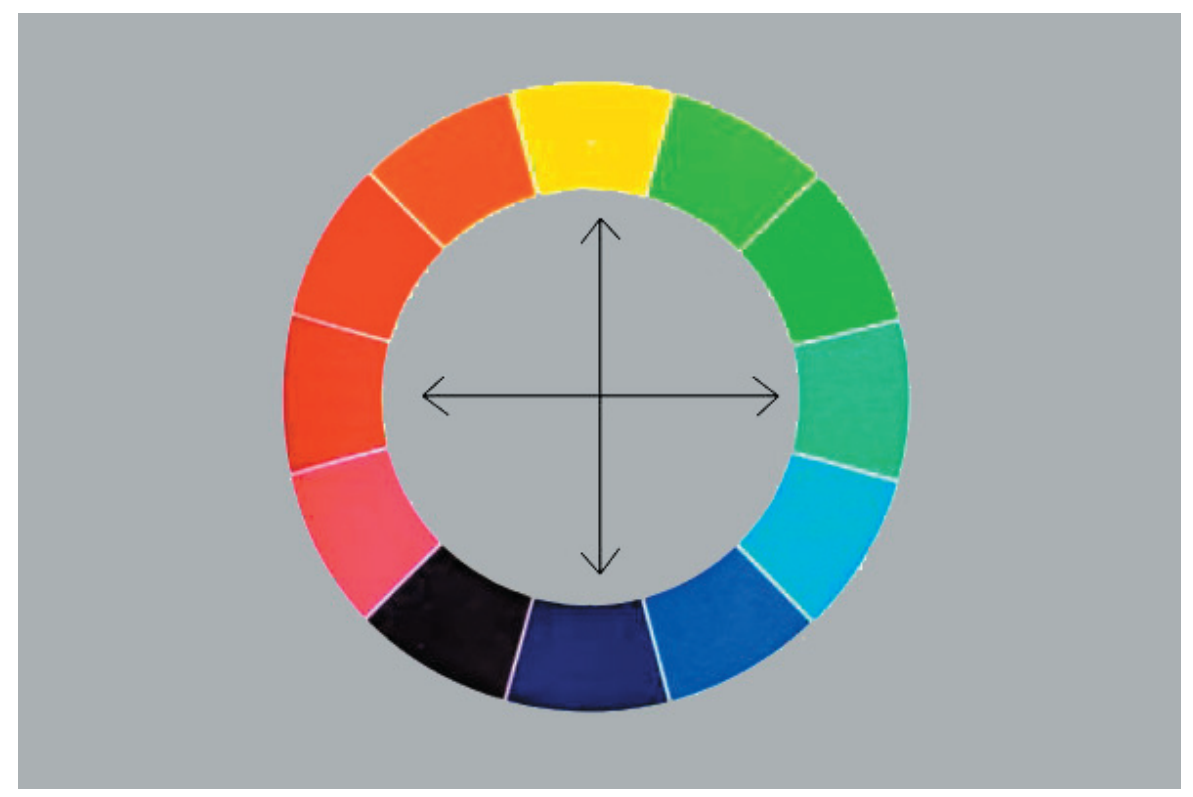

Figura 1. Rueda de colores.

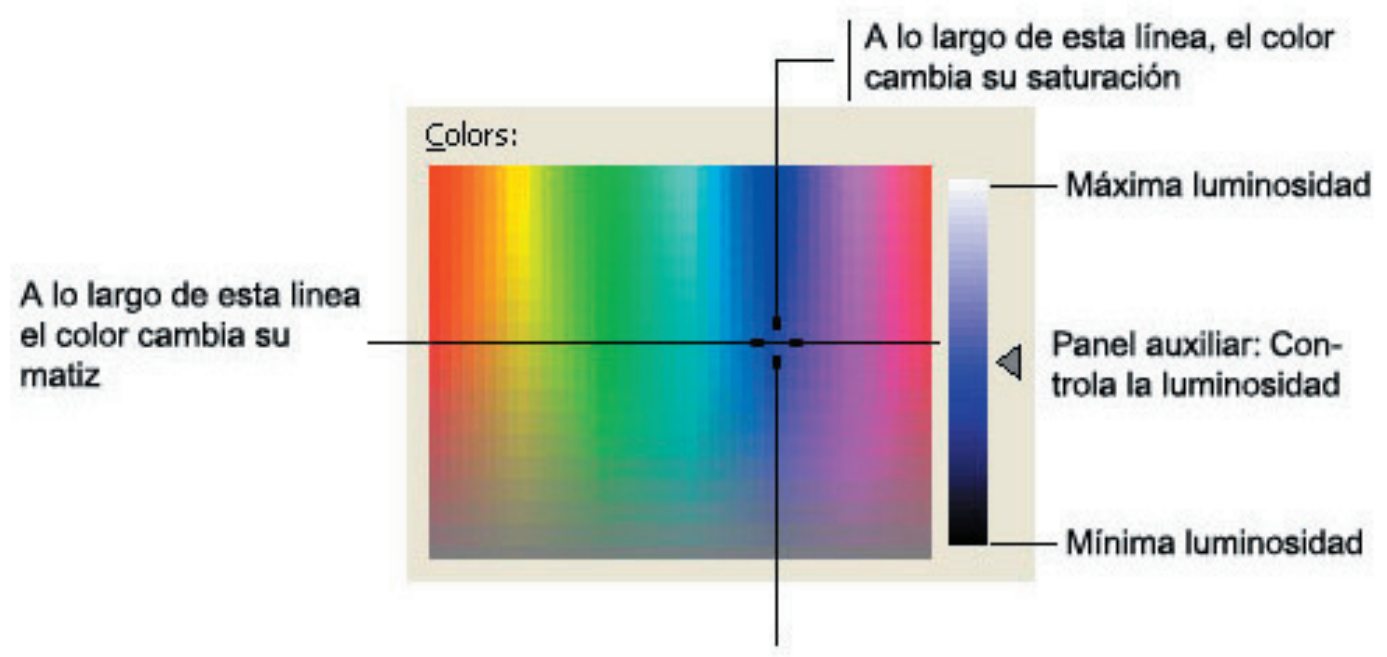

Figura 2. Editor de colores de Microsoft PowerPoint 2000.

RGB (red, green, blue). Los receptores visuales del ojo son del tipo RGB y es la que debemos utilizar en la presentación, ya que representa perfectamente la percepción humana del color.

Cada color tiene su saturación o intensidad, dependiendo de su grado de mezcla con el gris neutro. La figura 2 muestra el editor de colores de PowerPoint. Deslizando el marcador hacia arriba o abajo, obtenemos diferentes intensidades de un mismo color.

También podemos variar la "negrura" o "blancura" de un color (luminosidad o brillantez) deslizando el marcador del panel auxiliar de la derecha de la figura 2 hacia arriba (zona de blancos) o hacia abajo (zona de negros).

Johann Wolfgang Goethe, estudió el efecto psicológico de los colores, y los dividió en colores "cálidos" y colores "fríos". Los colores cálidos (rojo, naranja, amarillo) proporcionan una sensación de calidez, cercanía y viveza. Los colores fríos (verde, violeta y azul), corresponden a la mitad de la rueda de colores centrada en el azul ofrecen una impresión de tranquilidad, frescor y lejanía. Estas y otras connotaciones adicionales pueden aplicarse al elaborar una presentación. Si se desea, se puede seleccionar un determinado color de fondo relacionado con el tema que se expone. Por ejemplo, para hablar de hemorragias cerebra- 


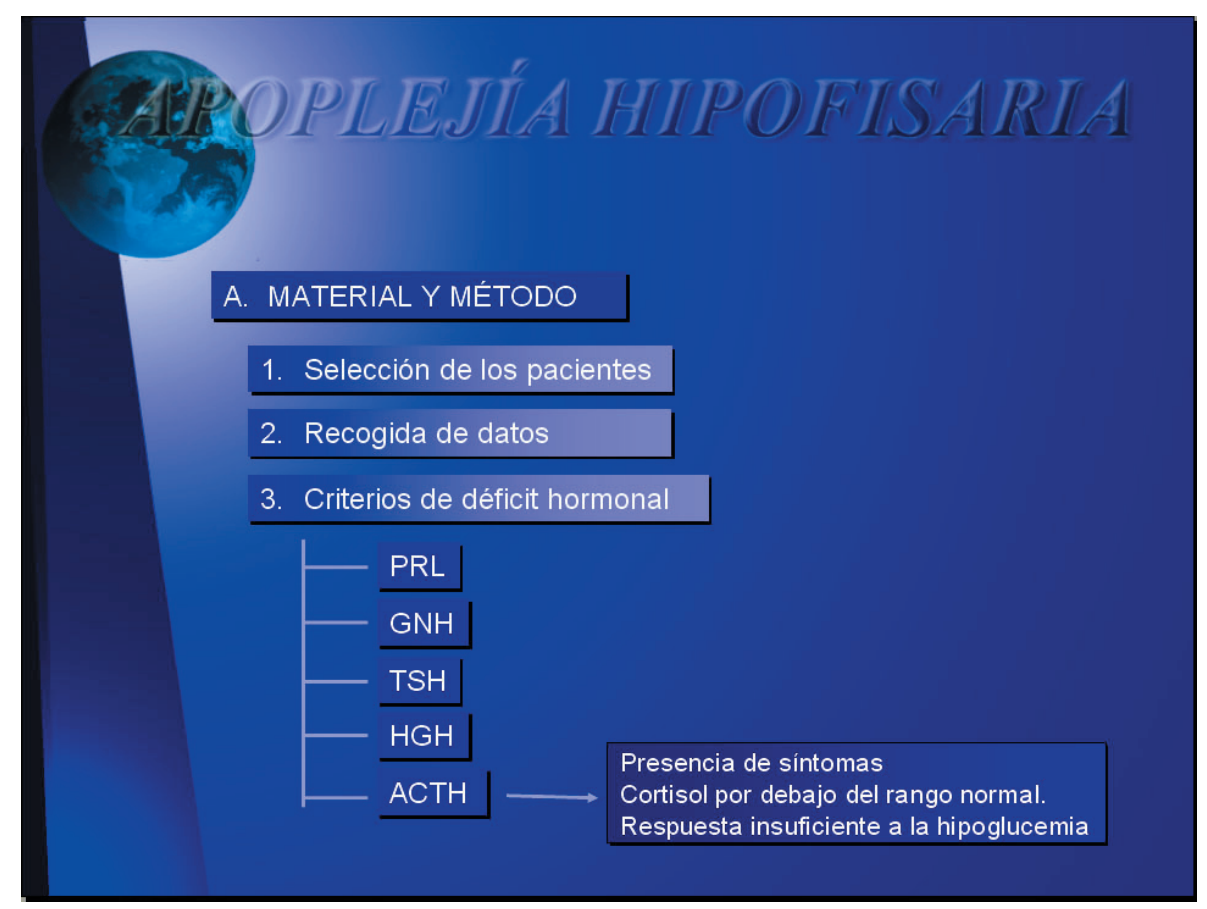

Figura 3. Armonía monocromática.

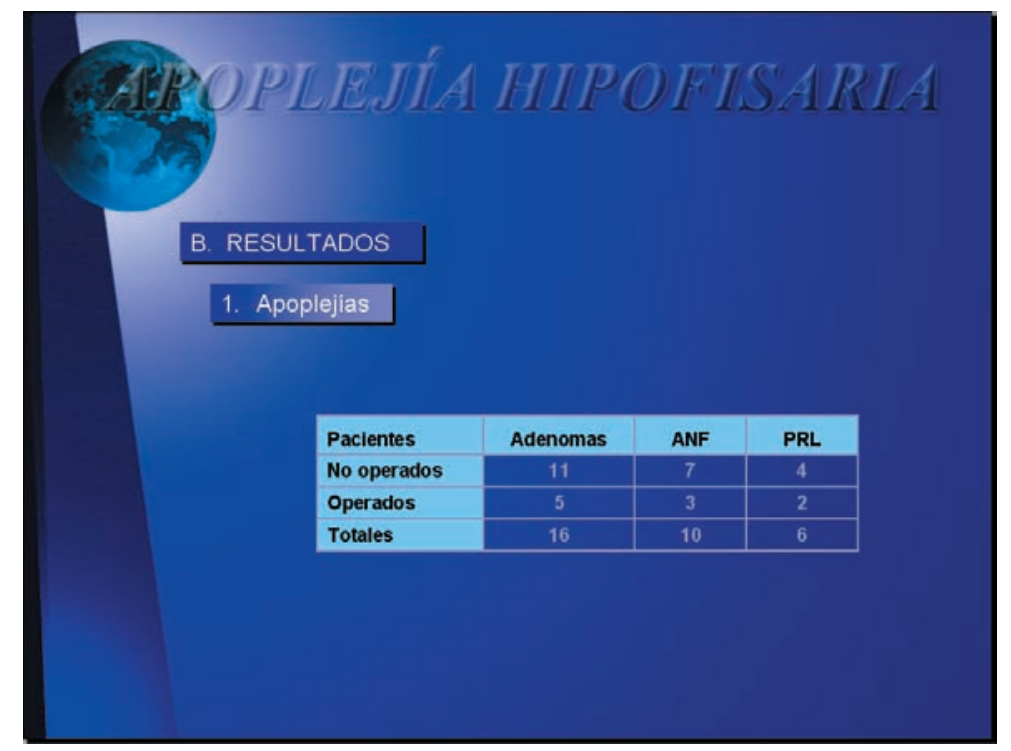

Figura 4. Armonía de análogos.

les, el color rojo en sus diferentes grados de saturación y brillantez sería muy apropiado.

\section{La paleta de colores de la presentación}

La disponibilidad de colores es muy amplia. Sin embargo, la diversidad distrae y confunde al espectador. No hay que olvidar que la presentación debe apoyar de manera sutil lo que el orador expone. Se impone, por tanto, una armonía de colores:

\section{Armonía monocromática}

Es sencilla, sobria y elegante. Consiste en elegir un color y sus variantes de luminosidad, que iremos distribuyéndo de manera jerarquizada entre el fondo, títulos, líneas, flechas y etiquetas de texto con relleno, degradados y el propio texto (Fig. 3).

\section{Armonía de análogos}

Ocupan posiciones inmediatamente contiguas en la rueda de colores. Por su parecido, armonizan muy bien 


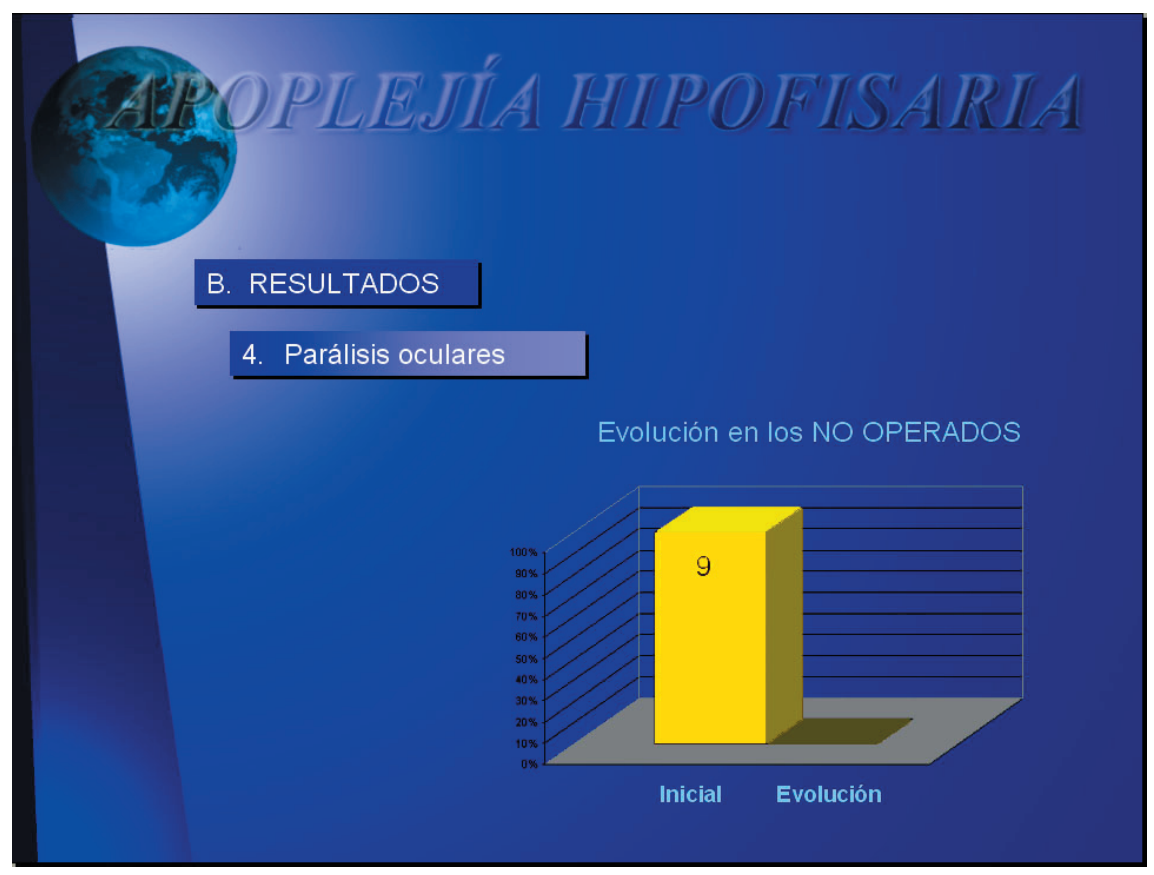

Figura 5. Armonía de complementarios.

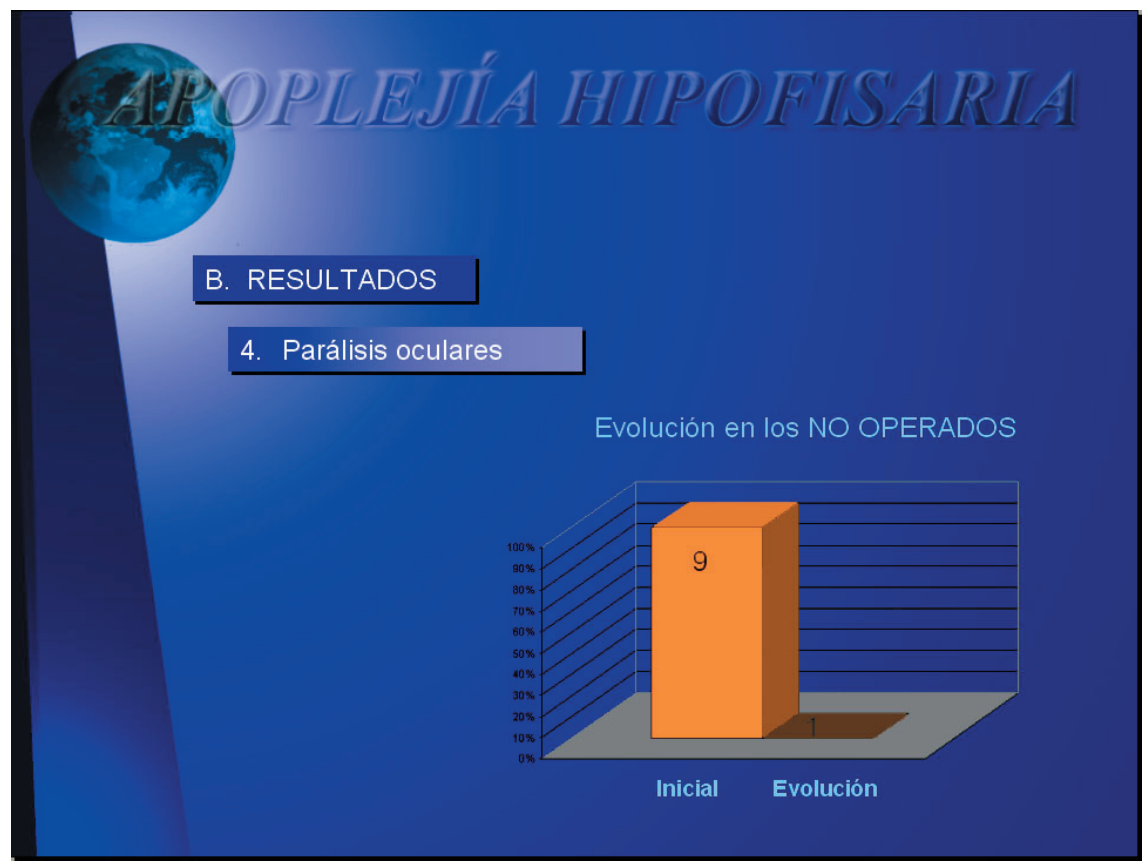

Figura 6. Armonía de complementarios divididos .

entre sí (Fig. 4).

\section{Colores complementarios o de contraste}

Ocupan posiciones opuestas en la rueda de colores. Se refuerzan y avivan mutuamente. Son idóneos para llamar la atención sobre un hecho concreto, ya que no deben de utilizarse con profusión (Fig. 5).

\section{Colores complementarios divididos}

Son los que están inmediatamente adyacentes a los complementarios, con lo que el contraste es menos dramático (Fig. 6), pero sirve para el mismo fin.

\section{Armonía de tres colores o triada}

Están formadas por tres colores equidistantes entres si en la rueda cromática. (Fig. 7). 


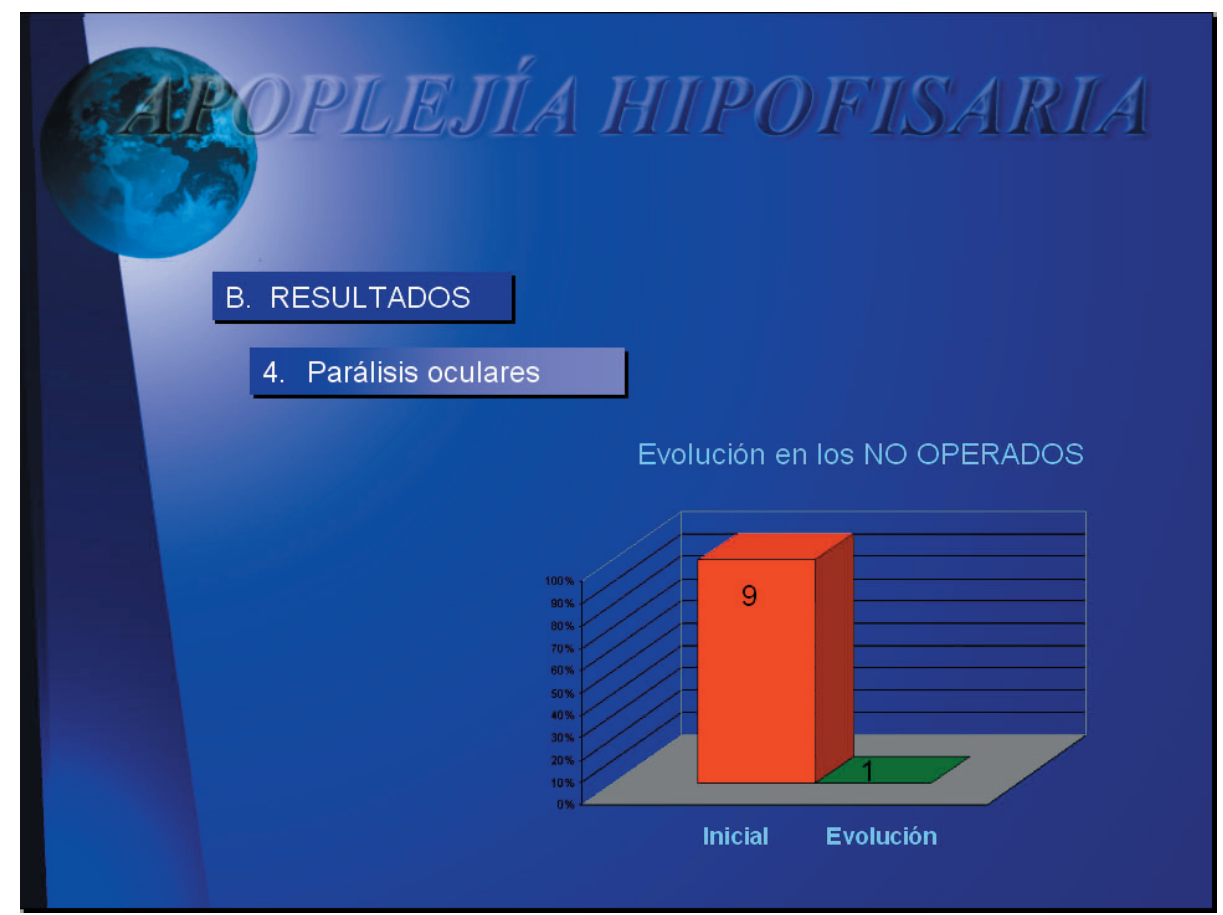

Figura 7. Triada.

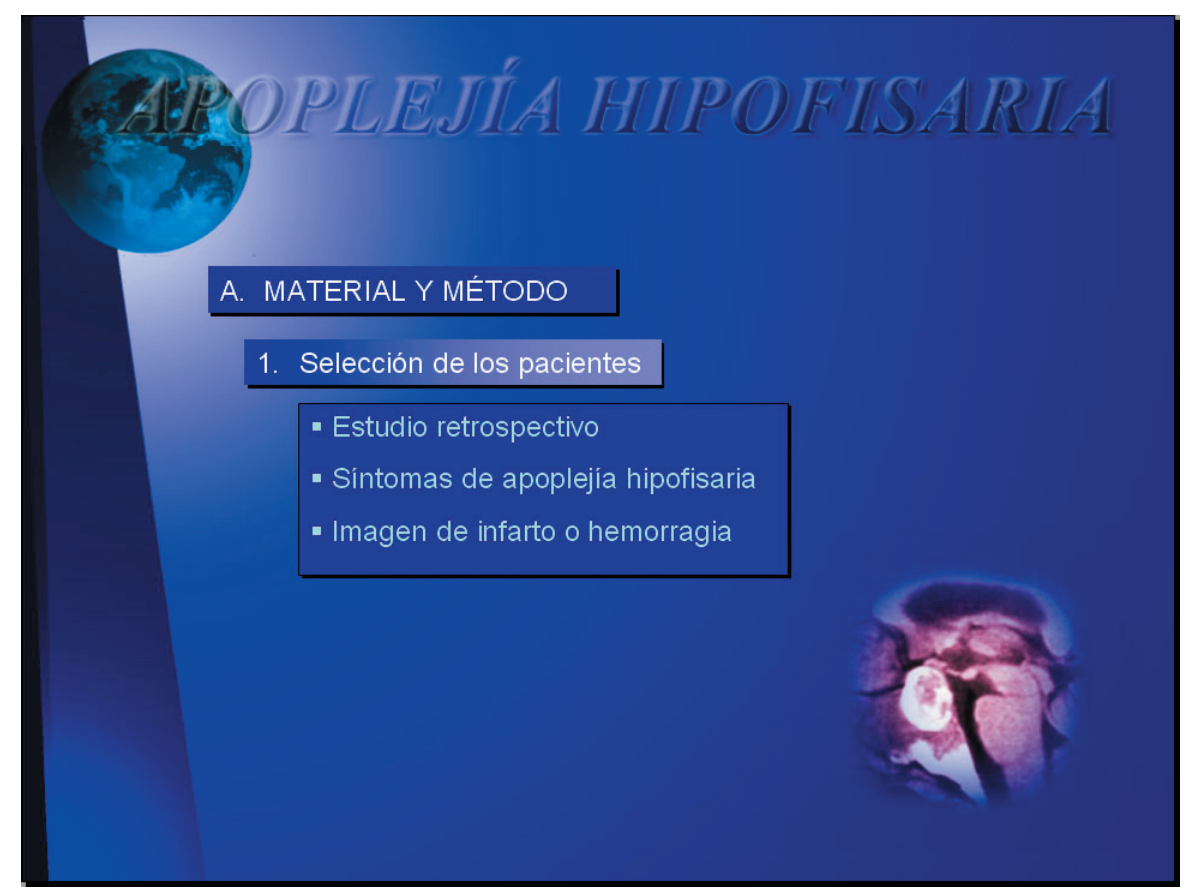

Figura 8. Equilibrio en el volumen y en el espacio.

Se pueden utilizar una doble o triple armonía de complementarios y combinaciones más elaboradas como tétradas, etc., pero raramente una presentación científica necesita tanta diversidad de colores.

El negro, el blanco y el gris combinan bien con cualquier color y los realzan. Los colores pasteles (versiones matizadas de los colores) son agradables y relajantes.

Una vez que se ha elegido la paleta de colores para la presentación, es necesario distribuirla por cada uno de los elementos de la diapositiva, pero intentando mantener el mismo criterio durante toda la exposición. En consecuencia, el color del fondo, al igual que su diseño y dibujo, no 
deben de cambiar hasta el final.

Existen programas muy útiles que ayudan al manejo y elección de los colores, como el ColorImpact (http: //www.tigercolor.com/) o el Color Wheel Pro (http:// www.color-wheel-pro.com/) entre otros.

\section{El color en el texto}

En cuanto al color, el texto debe de tener asignado un matiz, saturación y luminosidad, que deben de mantenerse constantes a lo largo de toda la exposición y encontrarse en la paleta de colores seleccionada para la presentación. Su condición imprescindible es que destaque sobre el color del fondo, para que su lectura sea fácil. Generalmente debe seleccionarse un color armónico con el del fondo de la diapositiva, pero muy bien diferenciado por su saturación o por su luminosidad. De manera puntual, puede destacarse una palabra o frase utilizando un color complementario (o de la división de un complementario) del color elegido para la superficie situada detrás de él o del fondo de la diapositiva.

\section{El relleno de los cuadros de texto}

Es importante mantener una jerarquía conceptual de los distintos capítulos de la presentación. Así, en una ponencia sobre un trabajo de investigación, los capítulos de Introducción, Material y método, Resultados y Conclusiones, pertenecerían todos a un mismo primer nivel jerárquico. Los subapartados de cada uno de esos capítulos son un escalón inferior y así sucesivamente. Conviene diferenciar de manera visual estas jerarquías. La forma de hacerlo es con el tipo de texto y su tamaño, pero también con relleno de los cuadros de texto de los encabezados. A este respecto, puede modularse la intensidad de o brillantez del color, así como utilizar degradados del mismo. Los más oscuros para los encabezados primarios, para después ir disminuyendo en intensidad o en brillantez en las etiquetas de los subapartados, terminando por el cuadro de texto sin relleno en los puntos finales. Las posibilidades son muchas, siempre que se mantenga un nexo racional y una jerarquía homogénea que se repite en todos los capítulos.

\section{La Dinámica visual}

Al igual que con los colores, la transición de las diapositivas debe de ser sencilla y uniforme a lo largo de toda la exposición. El movimiento distrae al espectador y si es exagerado, confunde y cansa. De manera excepcional, puede interesar llamar la atención con un cambio, como cuando se inicia un tema distinto al que se venía hablando. En otras ocasiones, lo ideal es que la transición no se note:

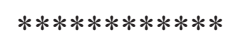

\section{Técnica de la transición de diapositiva imperceptible}

Supongamos que en un capitulo hay varios subapartados. Estamos interesados en que cada diapositiva apoye al orador en cada uno de esos subapartados, pero no queremos que el espectador pierda la referencia de aquel y de los encabezamientos de los subapartados. Deseamos que estos permanezcan a la vista para que el oyente mantenga la orientación de la ubicación conceptual del tema. Lo que se quiere es que las etiquetas de texto de los subapartados permanezcan visibles, al tiempo que se repliegan los textos o figuras utilizados para explicarlos y aparezca en pantalla el encabezamiento del siguiente subapartado que se va a desarrollar (Fig. 3). Esto se puede conseguir de dos formas:

1. Superponiendo en la misma diapositiva todas las etiquetas, tablas y figuras de cada uno de los apartados, dándoles un puesto en la animación de entrada y añadiéndole uno de salida a los destinados a desaparecer. Esto es una solución engorrosa cuando los objetos son muy numerosos.

2. Haciendo tantas copias de la diapositiva como se necesite; cada una sin los elementos de la anterior que nos interese quitar, pero dejando los que se quiere que permanezcan e introduciendo en la nueva diapositiva el subapartado que se vaya a desarrollar. Es fundamental quitar la animación de todos los objetos que ya han aparecido en las diapositivas anteriores y animar sólo el elemento nuevo entrante. La transición de la diapositiva no debe de tener movimiento extrínseco, siendo el de "Disolver" el mas apropiado, ya que provocará este efecto de desaparición en los objetos de la diapositiva anterior que no van a aparecer en la siguiente. En cada nueva diapositiva, el primer elemento nuevo deberá aparecer con una animación espontánea "after previous".

De los dos métodos, este último es el más fácil para trabajar.

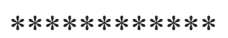

\section{La animación del texto}

Todo lo que se ha dicho para el color y la transición de la diapositiva, es válido para los textos: sencillez en la animación. Sólo de manera excepcional será oportuno que una palabra aparezca en escena como cayéndose letra a letra desde un tercer piso y rebotando en el suelo, en especial si no se va a contar un "tropezón" jocoso relacionado con ella. Sólo en la primera y última diapositiva es aceptable animaciones de texto llamativas.

Como se dijo antes, a los textos hay que dotarlos de jerarquía dentro de la exposición. Además del tipo de letra, 
tamaño y relleno del cuadro de texto, se puede utilizar la forma en la que se introduce en el campo visual, es decir, la animación.

Si se emplea un "Fade in" (aparición por tinción progresiva) para la introducción de la primera etiqueta de capítulo, se debe de emplear la misma animación para las restantes etiquetas de capítulos. Del mismo modo, si se emplea un barrido (descubrir de manera progresiva y en una dirección determinada) para una etiqueta de segundo nivel, todas sus homólogas deberán animarse igual y así sucesivamente. Esta uniformidad no distraerá al espectador y lo preparará de manera subliminal para el nuevo apartado.

La animación de los gráficos

El gráfico es un objeto voluminoso dentro de la diapositiva y tiende a hacerse dueño de ella. Una forma de evitarlo es integrarlo en su fondo, de manera que no parezca un elemento superpuesto. Esto se consigue haciendo que las paredes del gráfico sean transparentes, dejando traslucir lo que hay detrás de ellas. El blanco, negro y gris son colores muy apropiados para los ejes de coordenadas, a condición de que contrasten con el fondo. Por el contrario, a las líneas y barras de resultados se les debe de asignar un color complementario (Fig. 5), de la división del complementario (Fig. 6) o jugar con una triada (Fig. 7) o tétrada, según el número de colores que se necesite.

Es conveniente evitar la animación extrínseca en la entrada del gráfico en el campo visual. Sin embargo, la animación intrínseca es apropiada para resaltar las explicaciones del orador. Así, se puede hacer que las líneas de resultados asciendan o desciendan mediante barridos laterales en el momento apropiado o las barras crezcan una a una, desde la base del gráfico, utilizando el barrido ascendente conforme la explicación del ponente avanza.

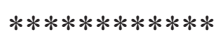

\section{Técnica de la transparencia y dinámica del gráfico}

No es complicado conseguirlo, pero la condición es que el gráfico esté en formato "GIF", que es el que permite elegir un color como transparente (Grafic Interchange Format: es un formato de compresión de imágenes con paletas personalizadas de hasta 256 colores).

Primero se crea el gráfico. En el PowerPoint se despliega el menú "Insertar" y se elige "Gráfico" o "Chart ". El programa inserta un patrón de gráfico en la diapositiva. Los pasos siguientes son sencillos:

1. Eliminar las columnas o las filas que no interesen mediante un doble "click" con el ratón sobre sus celdas de encabezado y suprimiendo las filas o colum- nas vacias, hasta lograr el tipo de gráfico que se adapte a nuestras necesidades.

2. Escribir las leyendas de los respectivos ejes y se añaden los valores en las celdas que les correspondan.

3. Cambiar el color de las barras a un complementario del color de fondo de la diapositiva, haciendo doble "click" en ellas.

4. Asignar un mismo color al área del gráfico y a las paredes del gráfico (no de su suelo), distinto del color asignado para las barras. Se logra haciendo doble "click" sobre ellas o eligiéndolo en el menú que se despliega con el botón derecho del ratón. Este es el color que vamos a elegir después como transparente, de manera que no importa el color de que se trate.

5. Con el mismo sistema podemos cambiar el color del texto del gráfico, eligiendo uno que sea bien visible sobre el color del fondo y que esté en consonancia con el color que hemos elegido para el texto general de la presentación.

6. Ahora que tenemos conformado el gráfico final, lo podemos utilizar como patrón para crear un gráfico sin las barras y otros tantos gráficos con cada una de las barras sobreañadidas. Lo único que tenemos que modificar para uniformarlos son los ejes de las coordenadas, de manera que aunque las barras tengan distintos valores los ejes sean comunes e iguales en su escala para todos ellos. Esto se logra eligiendo un valor igual o por encima del que tenga la barra más alta. Después, haciendo doble "click" en línea de ordenadas de cada gráfico y ajustando sus valores a los de la escala común para todos los gráficos.

7. El gráfico que genera el programa no está en formato "GIF", por lo que hay que convertirlo. Se logra seleccionando el gráfico con un "click" del botón derecho del ratón y seleccionando "guardar imagen..." y eligiendo el formato "GIF" como tipo de archivo y asignándole un nombre común de gráfico, pero con numeración desde el " 0 " del gráfico sin barras, hasta el que corresponda al último con todas las barras visibles.

8. A continuación, se borran todos los gráficos de la diapositiva o si se desea guardarlos de manera provisional hasta que comprobemos que no hay que modificar nada, se crea una nueva diapositiva que será la definitiva.

9. Con la diapositiva en blanco, se insertan de uno en uno, cada uno de los gráficos que hemos creado en formato "GIF", empezando por el " 0 " hasta el último que será el que represente el gráfico con todas las barras visibles. El orden de inserción es importante para que desde el gráfico sin barras se vayan superponiendo conforme se visualizan mas barras del gráfico.

10. Ahora, con los gráficos aún dispersos por 
la diapositiva, se procede a convertir el color de sus paredes en "transparente", para lo cual lo único que tenemos que hacer es señalarlo con el ratón después de presionar el botón de transparencia de la barra de "Imagen" o "Picture". Si esta barra de botones no está visible, hay que traerla a través del menú "Ver", eligiendo "barra de herramientas " $y$ seleccionando la de "Imagen".

11. Es el momento de proceder a la animación del gráfico. Al primero de ellos, podemos animarle con un "Fade" o "Disolve" o con cualquier otra que sea sutil. Después procedemos con la animación por orden de aparición de las barras, eligiendo para todos ellos una aparición a manera de barrido ascendente o "Wipe", seleccionando su entrada por "click" de ratón o de manera espontánea, cuando termine la anterior animación.

12. Por último, sólo nos queda agrupar todos los gráficos, de manera que parezcan uno solo. Esto se consigue seleccionándolos como grupo y presionando los botones de "alinear arriba" o "alinear a la izquierda" de la barra de dibujo. Si no está visible hay que traerla desde el menú "Ver" como hemos hecho antes para la de imagen. Si pese a esto, los botones de alineación no están visibles, hay que insertarlos desde el menú "Ver", "Barra de herramientas ", submenú "Customize".

13. Una vez agrupados como un solo gráfico, sólo hay que moverlo hasta la posición en que se desea que ocupe dentro de la diapositiva.

$* * * * * * * * * * * *$

\section{La distribución espacial de los objetos}

La diapositiva es como un lienzo que hay que rellenar. No sólo los colores y la animación condicionan la estética de la presentación y la jerarquía conceptual de los textos. La distribución espacial de los objetos tiene también una contribución y no menos importante.

\section{Espacio, tabulación y coordenadas del texto}

Cada etiqueta de texto necesita un espacio a su alrededor que no se le puede escamotear bajo ningún concepto. Es el espacio que le da "aire y vida visual"; unos atributos que facilitan su permeabilidad en el espectador. Por tanto, si es necesario, hay que repartir entre varias diapositivas el texto correspondiente a un apartado. Para que el espectador no pierda la referencia de ubicación del subapartado del que habla, se puede aplicar la técnica ya descrita, de la transición imperceptible de diapositiva.

También el lugar que ocupa una etiqueta de texto en la diapositiva es indicativo de su jerarquía en la exposición.
Así, todas las etiquetas de encabezado de capítulo, deben de tener siempre las mismas coordenadas. Las de los temas dependientes de ellos, una tabulación hacia dentro y así sucesivamente (Fig. 3).

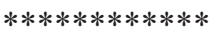

\section{Técnica para la uniformidad de las coordenadas de la etiqueta de texto}

Esto es fácil de conseguir con uno de estos dos métodos:

1. Con el botón derecho del ratón, se hace "click" en la etiqueta de texto. Se elige "Formato de la caja de texto" (Format text box) del menú contextual; en la pestaña de "posición" introducimos las coordenadas comunes de todas las etiquetas que tengan la misma jerarquía.

2. Se selecciona y copia la diapositiva que lleve ya la etiqueta en la posición que le corresponda y se pega a continuación de ella como diapositiva nueva. Esto se hace utilizando el panel izquierdo en vista normal del programa. Con esta operación, las etiquetas que nos interesen seguirán ocupando la misma posición en las diapositivas sucesivas. Sólo nos queda quitarles la animación a las que ya han aparecido en la diapositiva previa o, tal como se ha explicado antes, escribir el nuevo texto si se trata de un nuevo capitulo o subapartado que ha de ocupar la misma posición que su antecesor.

Este segundo método es el que menos tiempo consume.

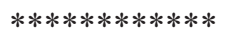

\section{Equilibrio en la distribución de los objetos}

Cada diapositiva es como una balanza sensible al peso de los objetos que se colocan sobre ella. Siempre se ha de procurar que la balanza esté en equilibrio visual. Esto se consigue con una distribución homogénea y racional de los objetos sobre el espacio disponible (Fig. 3). Pero no todos los objetos tienen el mismo peso. En la fotografía 8, vemos que la ubicación del "mundo" en la esquina superior izquierda, tiende a desequilibrar la diapositiva hacia ese lado, pese a que la arista de pirámide del dibujo del fondo ayuda a paliar esta pérdida de balance. Para compensarlo, se eligió la esquina inferior derecha para insertar la iconografía del paciente. El resultado es una distribución del espacio bastante equilibrada.

Como regla general y de manera similar a la fotografía, si una imagen ha de erigirse en la protagonista de una diapositiva, lo ideal es que ocupe el lugar donde el tercio medio de la diapositiva se une con uno de los tercios externos, siendo el derecho el más habitual (Fig. 7). 


\section{Consideraciones finales}

Una presentación puede hacerse en muy diversos estilos: formal, informal, seria, desenfadada, jocosa, etc. La impresión plástica de las diapositivas que apoyan la disertación debe de estar en consonancia con ese estilo y con el tema que se está exponiendo. Esto implica la elección cuidadosa del diseño y dibujo de fondo de la presentación, pero también del color, dinámica de las transiciones y de la animación de los objetos. Pero sea cual sea el estilo elegido, debemos tener siempre en mente estos principios:

1. Las diapositivas sólo deben de servir para realzar y apoyar la oratoria del ponente. Nunca deben de adueñarse de la disertación, relegando al conferenciante a un segundo plano o, lo que es peor, desluciendo o entorpeciendo la fluidez de su comunicación oral.

2. La evolución visual de la presentación tiene un gran impacto en el espectador, por lo que se ha de tener mucho cuidado en que no provoque la distracción del tema que está exponiendo el conferenciante. Por el contrario, debe empujar a su compresión sin que el espectador se percate de ello. Esto implica una cuidadosa combinación de colores y una animación sutil, que no desconcentre ni canse.

3. Los diferentes apartados de la presentación visual deben de estar bien definidos en su jerarquía mediante la forma, el color, la animación y su ubicación espacial, de manera que cada elemento nuevo no sólo no sobresalte al espectador, sino que por el contrario le incite a entrar de manera relajada en el desarrollo del tema.

\section{Comentario al trabajo Estética y dinámica visual de la presentación. Conceptos básicos de J. González-Tortosa}

El presente artículo expone algunos aspectos que deberían considerarse al preparar una presentación científica, en este caso elaborada con PowerPoint de Microsoft ${ }^{\circledR}$. Además de aspectos prácticos sobre el uso de este programa, el artículo también incluye otros conceptos básicos sobre como debe ser el contenido y el proceso de la presentación ("dinámica") para incrementar su eficacia. En un contexto en el que nuestra formación académica convencional no incluye este tipo de temas metodológicos, este artículo resume una información que puede ser muy útil para todos aquellos que inician su andadura en la elaboración de presentaciones científicas.

El elemento fundamental de las presentaciones científi-
"La fantasía, aislada de la razón, sólo produce monstruos imposibles. Unida a ella, en cambio, es la madre del arte y fuente de sus deseos" (Francisco de Goya).

\section{Bibliografía recomendada}

1. Durbin, C.G.: Effective Use of Tables and Figures in Abstracts, Presentactions, and Papers. Respir Care 2004; 49: 1233-1237.

2. Heller, E.: Psicología del color. Editorial Gustavo Gili. S.A. Barcelona 2004

3. Manchester Open Learning. Como hacer Presentaciones eficaces. Ediciones Gestión 2000. Planeta DeAgostini Profesional y Formación S.L. Barcelona 2004.

4. Palaoglu, O.: The art of scientific presentations. Acta Neurochir Suppl 2002; 83: 105-108.

5. Prasad, S., Roy, B., Smith, M.: The art and science of presentation: electronic presentations. J Postgrad Med. 2000; 46: 193-198.

6. Pulido, M.: El médico en las reuniones científicas: Como hablar en público para tener éxito. Med Clin (Barc) 2004; 123: 664-668.

7. Yebes, E.: Microsoft PowerPoint 2003. Editorial Anaya Multimedia S.A. Madrid 2004.

González-Tortosa, J.: Estética y dinámica visual de la presentación. Conceptos básicos. Neurocirugía 2006; 17 : 148-157.

Correspondencia postal: J. González Tortosa. Servicio de Neurocirugía. Hospital Universitario Virgen de la Arrixaca. Ctra Madrid-Cartagena. 30120 El Palamar. Murcia. cas sigue siendo el diseño de diapositivas. En los últimos años, la preparación de diapositivas ha seguido un proceso evolutivo evidente: del periodo blanco sobre fondo negro (Kodalite ${ }^{\circledR}$ ), se pasó por el periodo azul (fondo azul y texto blanco), hasta las diapositivas preparadas con programas informáticos como Harvard Graphics ${ }^{\circledR}$ y PowerPoint ${ }^{\circledR}$. Este último constituye, sin duda, el programa más popular en el momento actual en nuestro entorno. También en las presentaciones de PowerPoint podemos identificar un proceso "madurativo" en su elaboración. El principiante suele abusar de los efectos especiales que permite el programa, elaborando diapositivas en las que un derroche de textos y objetos aparecen y desaparecen desde todos los ángu- 
los, lloviendo, evaporándose o agrandándose en diversas modalidades. El usuario intermedio suele limitarse al uso de plantillas incluidas en el programa (los famosos templates) con algunos elementos adicionales. Por último, a medida que avanzamos en el conocimiento del programa, las diapositivas pierden su rigidez e incorporan cada vez más utilidades "libres". Los contenidos de este artículo pueden ayudarnos en este proceso.

Por último, no podemos olvidar que la "estética" y la "dinámica" de una presentación no pueden aislarse de su contenido y que el objetivo último debe ser conseguir que ésta sea didáctica, simple (lo que en ocasiones significa probablemente muy elaborada) y capaz de lograr que su mensaje persista. Esta empresa no siempre es fácil de conseguir.

M.A. Poca Barcelona
2006; 17: A-B

Comentario al trabajo Estética y dinámica visual de la presentación. Conceptos básicos de J. González-Tortosa

El trabajo revisado aborda un tema de gran interés en nuestra profesión, fundamental en la metodología actual de las presentaciones científicas. A lo largo del mismo se enumeran y resumen aspectos que pueden ayudar a la mejora de la presentación visual de las comunicaciones, de una forma sencilla y comprensible. La disponibilidad de innumerables herramientas informáticas está dando lugar a la existencia de una enorme variabilidad en el modo de presentación de las charlas, y la miríada de colores y elementos gráficos y de animación hace que en ocasiones la forma robe atención al fondo de los temas comunicados. Este trabajo expone las bases de un método que puede evitar estos problemas sin dañar, o mejorando más bien, la estética.

Hubiera sido deseable, sin embargo que la publicación incluyese la referencia a fuentes de conocimiento en las que la misma se sustenta, en forma de bibliografía.

A. Pérez Núñez R.D. Lobato Madrid 